\title{
Assessment of Psychosocial and Demographic Characteristics Related to Relapse in Schizophrenic Patients at Psychiatric Hospital of Assiut University.
}

\author{
Rasha Abdel-Harse Amin ${ }^{1}$, Ahmed Abdel Bakey Abdel Rahman², Nadia Abd Elghany Abd Elhameed ${ }^{3}$ \& \\ Manal Abo Elil Abo Elghiet ${ }^{4}$. \\ 1. Demonstrator of Psychiatric \& Mental Health Nursing, Faculty of Nursing, Assiut University, Egypt. \\ 2. Assistant Professor of Neurology and Psychiatry, Faculty of Medicine- Assiut University, Egypt. \\ 3. Assistant Professor of Psychiatric\& Mental Health Nursing, Faculty of Nursing, Assiut University, Egypt. \\ 4. Lecturer of Psychiatric \& Mental Health Nursing, Faculty of Nursing, Assiut University, Egypt.
}

\begin{abstract}
Relapse among schizophrenic patients is a major challenge for mental health service providers in Egypt. Relapse has negative consequences and it can affect to patients, their families, the mental health care providers and the country's economy. The study aimed to assess psychosocial and demographic characteristics associated with relapse in schizophrenic patients. Subjects and Method: A descriptive correlational research design was used in this study. purposive sample were utilized, consisting of 100 patients who have schizophrenia and accepted to share in the study. Tools of the study inculde personal data, socio economic assessment scale and a specially designed semistructured scale of relapse factors. Results: The participants consisted of 100 patients (58 males, 42 females), high statistically significant relation was found between socio economic level and age group "( $\mathrm{p}=0.007)$, no statistically significant relation was noticed between relapse factors and socio economic level. There is a negative correlation between social stigma and gender. The study concluded that there was a highly statistically significant relation between socio economic level and age group " $(\mathrm{p}=0.007)$. ,However there wasn't statistically significant relation between relapse factors and socio economic level, negative correlation between social stigma and gender Recommendation, Primary mental health care must be enhanced to prevent relapse among mentally ill patients, further studies are needed to investigate these factors on larger sample size with another tools and different settings
\end{abstract}

\section{Keywords: Psychosocial \& Demographic Characteristics Schizophrenia-Relapse.}

\section{Introduction}

Schizophrenia is a mental disorder characterized by abnormal behavior, strange speech, and a decreased ability to understand reality (Henry, et al., 2016). Schizophrenia is a mental illness with much stigma and misinformation associated with it. This often increases the distress to the person and his/her family (Paul, 2017).

Schizophrenia usually first appears when people are aged between 15 and 25 years, although it can appear later in life. The prevalence of schizophrenia is about one percent in the general population. About one third of people with schizophrenia experience only one or a few brief episodes in their lives (Caspi., et al., 2014). For others, it may remain a recurrent or lifelong health condition. The onset of illness may be rapid, with acute symptoms developing over several weeks, or it may be slow, developing over months or even years. During onset, the person often withdraws from others, gets depressed and anxious, and develops unusual ideas or extreme fears (Kastenbaum, 2015).
In a majority of people, schizophrenia is associated with functional impairment, including poor occupational attainment (Whitefor et al., 2015). However, with active intervention, most patients can achieve symptomatic remission ( Miklowitz, 2013). Psychotic relapse is common and is associated with significant deleterious effects for the individual and their family, including a worsening of clinical symptoms, impaired functionality, a reduced quality of life, and an increased financial burden for the patients and potentially their family members (Sohlberg \& Mateer, 2017) Relapse among schizophrenic patients is a major challenge for mental health service providers in Egypt. Relapse has negative consequences and it can affect to patients, their families, the mental health care providers and the country's economy The risk of patients harming themselves or others, education, employment status and of further stigmatization of the illness. Additionally, relapse may carry a biological risk. The repeated relapses also cause a burden on family, 
society and health system. Internationally, the factors commonly associated with relapse include poor adherence to treatment, substance abuse, comorbid psychiatric illness, a co-morbid medical and/or surgical condition and stressful life events (Seligman \& Darlin., 2017).

Similarly, Galletly, et al., (2016) stated that, understanding the factors associated with psychotic relapse in schizophrenia and engaging in management strategies to reduce the risk of such a relapse can be beneficial. Several factors have previously been associated with psychotic relapse. The factors most commonly cited include treatment non-adherence, comorbid depression or psychoactive substance misuse, and stressful life events .

Research studies done by W.H.O (2012) in a few nations have demonstrated that individuals can recuperate from mental issue like schizophrenia .The course of schizophrenia is said to be inconsistent, it has a tendency to go into incessant stage with relapse and dispatching design. Studies have demonstrates that around $20 \%$ of schizophrenic patients have a solitary lifetime scene with further relapse .Regardless of the likelihood of recovery, there are a few patients who continue going to the doctor's facility in light of a relapse.

Studies have demonstrates that around $20 \%$ of schizophrenic patients have a solitary lifetime scene with further relapse .Regardless of the likelihood of recovery, there are a few patients who continue going to the doctor's facility in light of a relapse Norcross \& VandenBos, (2018).

In a study that was done to track relapse in patients with schizophrenia it was discovered that $25 \%$ of subjects were admitted to intense care within three months of their last admission ( Rice, et al., 2018).

\section{Significance of the study}

Schizophrenia is a challenging psychiatric disorder in developing countries and most of schizophrenic patients experiencing multiple relapses during the course of the illness. Schizophrenia is one of the main components of healthcare expenditure in developed countries, accounting for $1.9 \%$ of the total healthcare budget in clinically, and from the care perspective as well, European countries and $2.5 \%$ in the United Status (Semrau et al., 2015).

In addition to, the previous studies suggest that the risk of relapse in patients with schizophrenia is approximately 3.5\% per month ( Alvarez-Jimenez et al., 2012)

The Egyptian literature has very few studies relapse related factors among schizophrenic patients. None of these studies have investigated the patient's own perspective on the factors that may cause the relapse.
Relapse in schizophrenia has a great deal of impacts to patients, caregivers, the wellbeing sector and the nation's economy (Abdel Salam \& Gaber, 2017) .So, the present study could be helpful in providing information that accurately assists in the prevention of relapse of patients with schizophrenia.

Aim of the study

Assess psychosocial and demographic characteristics associated with relapse in schizophrenic patient.

Research question:

What are the relationships among patients' sociodemographic data and their relapse?

Is there relation between psychosocial characteristics and relapse in schizophrenic patients?

\section{Subjects \& Methods \\ Research design}

Adescriptive correlational research design was used in this study.

\section{Research Setting}

The study was carried out at inpatient psychiatric unit of psychiatric and neurological hospital at Assiut University.

\section{Sample}

Non probability (purposive) sample was be utilized, consisting of 100 patients who have schizophrenia.

\section{Inclusion criteria}

- Patients of schizophrenia aged between 18 and 65 years and were accompanied by relatives, and/or spouse.

- Patients who agree or accept to participate in the study.

\section{Exclusion criteria}

- Patients who were having mental retardation.

- Patients who were in acute stage of schizophrenia.

- Patients who had relapse after fever or some medical illnesses.

Tools of data collection

Each participant was evaluated through the following tools:

Demographic characteristics data sheet

This tool was developed by the researcher to collect the information about the Socio demographic data such as (age, gender, education level, housing, occupation and marital status).

Socio economic assessment scale (Abd-EL-Tawab, 2004)

This scale was designed by (Abd-El-Tawab,2004) to assess socioeconomic status of the family and consists of 4 dimensions, which include the following:-

- Parents' level of education.

- Parents' occupation.

- Total family monthly income.

- Life style of the family. 
The scoring system of this tool uses two points scale (Yes- No). Each main variable involves a set of level or branches, and these levels are weighted on a graded scale from 1 up to 5. Each level has a score; the sums of these scores give the total score of the variables. The total (raw) score for an individual can be obtained from an equation that depends upon these variables.

\section{A specially designed semi-structured scale}

This tool was developed by (Vijay, 2016) The scale was modifided and translated into Arabic language by the researcher and checked for its content validity and reliability.which was done by jury from 5 experts 3 professor of psychiatric nursing and 2 professors of psychiatric medicine. It was used to elicit the factors which responsible for relapse in schizophrenic patients. It has seven sub-groups which contain forty questions. Seven sub-group contain following

1. Factors influencing the patient.

2. Individual factors of the patient.

3. Social factors and family perception.

4. Societal stigma.

5. Religious myth and superstition.

6. Gender difference.

7. Rehabilitation of patient in the community.

Based on the opinion of jury, the scale categories were modified to be formed into a five point, ranging from (1) strongly agree to (3)strongly disagree .

- The translated scale had shown adequate validity (0.85) based on jury opinion. Reliability test was done to the modified scale by using cronbach Alpha it was (0.72).

\section{Procedure}

\section{the following steps}

1. An official permission from the general director of the hospital and the head of psychiatric and neurological department were taken to facilitate the data collection.

2. Oral permission of patient was done.

3. At the beginning, the researcher introduced herself to the patients and discussed to them aim of the study.

4. The researcher met the patients.

5. The tools sheets were filled by the researcher as following:

A total of family members or significant others accompanying patients with schizophrenia for readmissions or visiting patients with schizophrenia in the wards were selected by random sampling. Schizophrenia was diagnosed using Diagnostic and statistical manual of mental disorder, 4th edition text revision (DSM-IV-TR) criteria. Data were collected using semi-structured scale and analyzed using Statistical package for social science (SPSS) and presented in frequency tables.
Pilot Study

A pilot study was conducted at the beginning of the study . it was included (20) cases of total sample during the first 3 weeks of data collection to investigate the feasibility of data collection tools and their clarity ,no modification was done in the studied sample and number of pilot study not included to the study sample.

\section{Ethical considerations}

1. Research proposal was be approved from ethical committee in the faculty of nursing.

2. The study was follow common ethical principles in research.

3. There was no risk for study subjects during application of the research.

4. Oral consent will be obtained from patient that are willing to participate in the study, after explaining purpose of the study.

5. Patients have the right to refuse to participate and/or withdraw from the study at any time

6. Study subject Privacy was be considered during collection of data.

7. Confidentiality of obtained data was be maintained and ensure for every studied samples before starting data collection.

\section{Statistical analysis}

The data were tested for normality using the Anderson-Darling test and for homogeneity variances prior to further statistical analysis. Categorical variables were described by number and percent $(\mathrm{N}$, $\%)$, where continuous variables described by mean and standard deviation (Mean, SD).We compare between continuous variables ANOVA TEST . A two-tailed $\mathrm{p}<0.05$ was considered statistically significant. All analyses were performed with the IBM SPSS 20.0 software . 


\section{Result}

Table (1): Personal and clinical data of the studied schizophrenic patients $(n=100)$

\begin{tabular}{|c|c|c|}
\hline Personal and clinical data & No & $\%$ \\
\hline \multicolumn{3}{|l|}{ Age group } \\
\hline Less than 30 years & 37 & 37.0 \\
\hline from $30-40$ years & 37 & 37.0 \\
\hline More than 40 years & 26 & 26.0 \\
\hline Mean \pm SD(range) & \multicolumn{2}{|c|}{$34.21 \pm 9.45(18-54)$} \\
\hline \multicolumn{3}{|l|}{ Gender } \\
\hline Male & 58 & 58.0 \\
\hline Female & 42 & 42.0 \\
\hline \multicolumn{3}{|l|}{ Residence } \\
\hline Rural & 6 & 6.0 \\
\hline Urban & 94 & 94.0 \\
\hline \multicolumn{3}{|l|}{ Housing } \\
\hline Live Alone & 41 & 41.0 \\
\hline With Family & 59 & 59.0 \\
\hline \multicolumn{3}{|l|}{ Marital status } \\
\hline Single & 43 & 43.0 \\
\hline Married & 51 & 51.0 \\
\hline Divorced & 3 & 3.0 \\
\hline Widow & 3 & 3.0 \\
\hline \multicolumn{3}{|l|}{ Education } \\
\hline Illiterate & 17 & 17.0 \\
\hline Read and write & 36 & 36.0 \\
\hline Higher education & 7 & 7.0 \\
\hline \multicolumn{3}{|l|}{ Occupation } \\
\hline Not work/ House wife & 94 & 94.0 \\
\hline Work & 3 & 3.0 \\
\hline \multicolumn{3}{|l|}{ hospital admission } \\
\hline In voulantary & 100 & 100.0 \\
\hline \multicolumn{3}{|l|}{ Medical Disease } \\
\hline Yes & 8 & 8.0 \\
\hline No & 92 & 92.0 \\
\hline
\end{tabular}

Table (2): Distribution of Socio economic Level among studied schizophrenic patients (n=100)

\begin{tabular}{|l|c|c|}
\hline \multicolumn{1}{|c|}{ Socio economic status } & No. & \% \\
\hline Low & 14 & 14.0 \\
\hline Middle & 65 & 65.0 \\
\hline High & 21 & 21.0 \\
\hline Mean $\pm S D($ range) & \multicolumn{2}{|c|}{$25.68 \pm 4.06(19-36)$} \\
\hline
\end{tabular}

Table (3): Distribution of the mean scores of relapse factors among the studied schizophrenic patients $(\mathrm{n}=100)$

\begin{tabular}{|l|c|c|c|c|}
\hline \multicolumn{1}{|c|}{ Relapse factors } & Max Score & Min score & Mean \pm SD & $(\boldsymbol{\%})$ \\
\hline Patient Factor & 27 & 5 & $13.48 \pm 2.48$ & 49.9 \\
\hline Individual Factor & 15 & 12 & $5 \pm 0$ & 33.3 \\
\hline Social Factor & 55 & 9 & $13.38 \pm 1$ & 24.3 \\
\hline Social Stegma Factor & 15 & 15 & $7.26 \pm 2.14$ & 48.4 \\
\hline relgion Factor & 9 & 5 & $4.67 \pm 1.05$ & 51.9 \\
\hline Gender difference & 12 & 5 & $4.05 \pm 0.22$ & 33.8 \\
\hline Comunnity Rehabilitation & 9 & 12 & $3.07 \pm 0.26$ & 34.1 \\
\hline Total Relaps Score & $\mathbf{1 4 2}$ & $\mathbf{5 5}$ & $\mathbf{5 0 . 9 1 \pm 4 . 5 5}$ & 35.9 \\
\hline
\end{tabular}


Table (4): Relationship between relapse factors and Socio economic Level of studied schizophrenic patients $(\mathbf{n}=\mathbf{1 0 0})$.

\begin{tabular}{|l|c|c|c|c|c|}
\hline \multirow{2}{*}{\multicolumn{1}{c|}{ Relapse factors }} & \multicolumn{5}{c|}{ Socio Economic Level } \\
\cline { 2 - 7 } & Low $(\mathbf{n}=\mathbf{1 4})$ & Middle(n=65) & High(n=21) & Total(n=100) & \multirow{2}{*}{ P. value } \\
\cline { 2 - 7 } & Mean \pm SD & Mean \pm SD & Mean \pm SD & Mean \pm SD & \\
\hline Patient Factor & $13 \pm 2.94$ & $13.74 \pm 2.17$ & $13 \pm 3.02$ & $13.48 \pm 2.48$ & 0.367 \\
\hline Individual Factor & $5 \pm 0$ & $5 \pm 0$ & $5 \pm 0$ & $5 \pm 0$ & - \\
\hline Social Factor & $13.14 \pm 0.86$ & $13.4 \pm 0.92$ & $13.48 \pm 1.33$ & $13.38 \pm 1$ & 0.611 \\
\hline Social Stegma Factor & $6.93 \pm 1.69$ & $7.37 \pm 2.28$ & $7.14 \pm 2.03$ & $7.26 \pm 2.14$ & 0.757 \\
\hline relgion Factor & $4.21 \pm 1.25$ & $4.75 \pm 0.95$ & $4.71 \pm 1.19$ & $4.67 \pm 1.05$ & 0.218 \\
\hline Gender difference & $4 \pm 0$ & $4.05 \pm 0.21$ & $4.1 \pm 0.3$ & $4.05 \pm 0.22$ & 0.444 \\
\hline Comunnity Rehabilitation & $3.14 \pm 0.36$ & $3.05 \pm 0.21$ & $3.1 \pm 0.3$ & $3.07 \pm 0.26$ & 0.392 \\
\hline Total relaps & $49.43 \pm 5.06$ & $51.35 \pm 3.84$ & $50.52 \pm 6.03$ & $50.91 \pm 4.55$ & 0.327 \\
\hline
\end{tabular}

Table (5): Correlation between relapse and Socio economic Level For studied schizophrenic patients (n=100)

\begin{tabular}{|l|c|c|}
\hline \multirow{2}{*}{} & $\mathbf{R}$ & \multicolumn{2}{|c|}{ Socio economic class } \\
\cline { 2 - 3 } & & 0.662 \\
\hline Patient Factor & -0.044 & - \\
\hline Individual Factor & - & 0.478 \\
\hline Social Factor & 0.072 & 0.954 \\
\hline Social Stegma Factor & 0.006 & 0.262 \\
\hline relgion Factor & 0.113 & 0.201 \\
\hline Gender difference & 0.129 & 0.781 \\
\hline Comunnity Rehabilitation & -0.028 & 0.950 \\
\hline Total relaps & 0.006 & \\
\hline
\end{tabular}

Table (6): Correlation matrix between personal and clinical data total and relapse factors among studied schizophrenic patients $(n=100)$

\begin{tabular}{|l|c|c|c|c|c|c|c|c|}
\hline \multirow{2}{*}{ Correlations } & & $\begin{array}{c}\text { Patient } \\
\text { Factor }\end{array}$ & $\begin{array}{c}\text { Social } \\
\text { Factor }\end{array}$ & $\begin{array}{c}\text { Social } \\
\text { Stigma } \\
\text { Factor }\end{array}$ & $\begin{array}{c}\text { religion } \\
\text { Factor }\end{array}$ & $\begin{array}{c}\text { Gender } \\
\text { difference }\end{array}$ & $\begin{array}{c}\text { Community } \\
\text { Rehabilitation }\end{array}$ & $\begin{array}{c}\text { Total } \\
\text { relapse }\end{array}$ \\
\hline \multirow{2}{*}{ Age } & $\mathrm{R}$ & 0.150 & -0.034 & 0.081 & 0.160 & -0.030 & 0.119 & 0.155 \\
\cline { 2 - 11 } & $\mathrm{P}$ & 0.137 & 0.736 & 0.423 & 0.112 & 0.771 & 0.239 & 0.125 \\
\hline \multirow{2}{*}{ Gender } & $\mathrm{R}$ & -0.059 & -0.162 & $\mathbf{- . 3 1 3 -}$ & -0.138 & 0.177 & -0.075 & $\mathbf{- . 2 4 3 -}^{* *}$ \\
\cline { 2 - 11 } & $\mathrm{P}$ & 0.561 & 0.108 & 0.002 & 0.171 & 0.079 & 0.460 & 0.015 \\
\hline \multirow{2}{*}{ Residence } & $\mathrm{R}$ & -0.070 & 0.012 & -0.107 & 0.081 & 0.058 & 0.069 & -0.061 \\
\cline { 2 - 11 } & $\mathrm{P}$ & 0.486 & 0.907 & 0.288 & 0.423 & 0.567 & 0.493 & 0.548 \\
\hline \multirow{2}{*}{ Housing } & $\mathrm{R}$ & 0.006 & -0.049 & 0.168 & 0.087 & 0.005 & 0.149 & 0.100 \\
\cline { 2 - 11 } & $\mathrm{P}$ & 0.956 & 0.626 & 0.094 & 0.392 & 0.963 & 0.139 & 0.321 \\
\hline \multirow{2}{*}{ Marital status } & $\mathrm{R}$ & 0.008 & -0.075 & 0.020 & 0.095 & 0.114 & 0.022 & 0.026 \\
\cline { 2 - 11 } & $\mathrm{P}$ & 0.938 & 0.460 & 0.847 & 0.348 & 0.257 & 0.829 & 0.799 \\
\hline \multirow{2}{*}{ Education } & $\mathrm{R}$ & 0.003 & 0.086 & -0.073 & 0.000 & -0.039 & 0.080 & -0.011 \\
\cline { 2 - 11 } & $\mathrm{P}$ & 0.974 & 0.397 & 0.471 & 0.997 & 0.703 & 0.426 & 0.914 \\
\hline \multirow{2}{*}{ Occupation } & $\mathrm{R}$ & 0.104 & 0.166 & 0.090 & -0.081 & -0.053 & -0.063 & 0.111 \\
\cline { 2 - 10 } & $\mathrm{P}$ & 0.302 & 0.100 & 0.371 & 0.424 & 0.603 & 0.534 & 0.272 \\
\hline \multirow{2}{*}{ Medical disease } & $\mathrm{R}$ & 0.013 & 0.001 & 0.019 & $\mathbf{- . 2 6 8 - * *}$ & 0.068 & $\mathbf{- . 2 0 8 -}{ }^{*}$ & -0.055 \\
\cline { 2 - 10 } & $\mathrm{P}$ & 0.901 & 0.988 & 0.854 & 0.007 & 0.504 & 0.038 & 0.589 \\
\hline
\end{tabular}


Table (1): Shows that (58\%) of the studied schizophrenic patients were males and $(42 \%)$ of them were Females .The majority (94\%) of them studied schizophrenic patients were live in urban area, While $(6 \%)$ of them were live in rural area. As regard to education, $(36 \%)$ of the studied schizophrenic patients were read and write, While $(17 \%)$ of them were illiterate. More than half $(51 \%)$ of the studied schizophrenic patients were married, While $(43 \%)$ of them patients were singles. The majority (94\%) of the studied schizophrenic patients did not work / House wife. All of the studied schizophrenic patients were admitted to hospital involuntary (100\%). The majority (92\%) of them had not medical disease

Table (2): Shows that about two thirds of studied schizophrenic patients had middle level of socio economic status $65 \%$, while $21 \%$ of them had high level of socio economic status and $14 \%$ of them had low level of socio economic status.

Table (3): Shows that relgion factor represents 51.9\% with Mean \pm SD $4.67 \pm 1.05$ which is the highest percent among relapse related factors, while social factor represents that $24.3 \%$ with Mean \pm SD $7.26 \pm 2.14$ is the lowest percent.

Table (4): Represent that no statistically significant difference were found between socio economic level and relapse factors.

Table (5): Illustrates that there is no statistically significant difference between relapse factors and socio economic level.

Table (6): represents that, gender is negatively and significantly Correlated with social stigma factor and the total relapse. However, medical disease is negatively and significantly correlated with religion and community rehabilitation as sub related relapse factors.

\section{Discussion}

Schizophrenia is a serious mental illness that interferes with a person's ability to think clearly, manage emotions, make decisions and relate to others. It is a complex, long-term medical illness, although schizophrenia can occur at any age, the average age of onset tends to be in the late teens to the early 20 s for men, and the late 20 s to early 30 s for women and most of schizophrenic patients experiencing multiple relapses during the course of the illness (Fortinash \& Worret., 2014).

The current study revealed that, more than half patients were males, The result showed the number of males more than females this could be due to the nature of the society and stigma discourage the females to visit the community mental health clinic and hospital. The finding is consistent with Winter et al., (2016) who reported that male preponderance was also seen by their studies .
Slightly more than one third of the sample was in the age of (25-35) years. This age indicates that schizophrenia affects the productivity and Quality of life (QOL) of individuals. This could be due to schizophrenia as a chronic disability illness that begins in young age groups and this is similar to what is documented in various literature. This finding is agree with Chabungbam., et al., ( 2016) who reported that the mean age of their sample was around thirty three years old for the relapsed group .

Concerning residence, the most studied schizophrenic patients were from urban areas in Egypt and which agree with the result of (Chabungbam., et al., 2016), who assessed psychosocial factor related to relapse in schizophrenia in China and found that this result may be due to the increased mental illness stigma in rural areas in Egypt that might affect the patients to seek help or visit any psychiatric facility (Sun, et al., 2014).

Concerning education, the study showed that almost all the studied patients can read and write and that is incongruent with the results of Chabungbam., et al., (2016), who reported that almost three thirds of the sample was illiterate. However, this finding was inconsistent with Chaurotia, et al., (2016), who found that $24 \%$ of the relapsed group were illiterate (Irish., et al., 2017). This could be interpreted by that schizophrenia affect cognitive functions negatively which consequently influence on educational level. Concerning the marital status of the studied sample, it was reported that slightly more than half of the sample were married. This finding is not on the same line of the study by San et al., (2013), who reported that majority of patients $(73.3 \%)$ were unmarried and divorced. This finding may be related to the stigmatizing nature of the mental illness that prevent most of the schizophrenic patients in the Egyptian society to be married as they considered less than normal people in responsability (Wedding \& Niemiec, 2014) However, this result is consistent with Abdel-Baki et al., (2011) who reported that the majority of his studied sample were married.

Slightly most of the sample reported that they have been not working and that not helped them to have enough income to meet their needs, this result due to most of the schizophrenic patients unemployed due to poor social skill and they did not have a job to earn income and they become dependent .This result is agreement with Bloom \& Tavrow, (2018) who reported that the majority of studied sample were not working.

The current study showed that all the studied sample were hospitalized involuntary because most of patient were less likely to have insight about their illness and not seek help from the mental health 
clinic and psychiatric hospitals. This finding disagree with a study that was done by Pfiffner, et al., (2014) in Germany who reported that most of the schizophrenic patients were hospitalized voluntary and seeking treatment to relief symptoms.

The present study showed that the majority of the studied schizophrenic patients did not have medical disease, this result due to most of patient diagnosis with schizophrenia and without other medical disease. This finding is agree with the results of Insel, (2010) who reported that most of the psychiatric patients did not have medical disease , while Tandon, et al., (2013) reported that majority of individuals diagnosed with schizophrenia were have medical disease which lead them to relapse because these diseases affect on metabolism and absorption of psychotic medication.

Regarding socioeconomic level the current study reported that the about two thirds of studied schizophrenic patients had middle level of socio economic status, this result due most of patients did not have enough income to compliance of medication and lead to relapse ,this finding is incongruent with the results of Werner, et al., (2007) who assessed socioeconomic status at schizophrenia patients ,reported that majority of studied schizophrenic patients had high level of socio economic status.

Regarding relationship between total relapse factors and socio economic level of schizophrenic patients , the current study revealed that no signifence difference was noticed between socio economic level and total relapse score,. This finding is incongruent with the results of San, et al., (2013) who reported that there was a significant difference between socio economic level and total relapse factors among schizophrenic patients. This result due to relapse occur between all patients regarding socio economic level

The current finding clarified that religion factor was represented among more than half of the studied sample as a relapse related factor with Mean \pm SD $4.67 \pm 1.05$ which is the highest percent, this finding agree with Haque., et al, (2015) who reported the same result, this result may be due to strong religious beliefs affects the patient's seeking help from psychiatric hospital and response to treatment and cause frequent relapse during the course of treatment. Regarding correlation between total relapse factors and personal and clinical data for studied schizophrenic patients, the present study showed that there was a negative correlation between social stigma and gender. This may be due to the nature of the society and stigma that discourage the females to seek help from the mental health clinic and psychiatric hospitals, Also negative correlation was found between religion factor and medical disease,
This result due to religious beliefs affects the patient's seeking treatment, negative correlation between community rehabilitation and medical disease due to community rehabilitation center not accessible to all patients due to its cost. As well as negative correlation between total relapse factors and gender, this result due to men with schizophrenia appears to have negative symptoms and recurrent relapse than woman. This finding is agree with Lorenz, (2016) who reported the same finding in his study in Germany about relapse factors in schizophrenia. Otherwise Webber, et al., (2014) reported that positive correlation between social stigma and gender at $\mathrm{p}(0.005)$, between religion factor and medical disease $\mathrm{p}(0.007)$, between community rehabilitation and medical disease $\mathrm{p}(0.006)$, respectively.

\section{Conclusions}

Based on the results of the present study, it can be concluded that:

- Religion factor is most influence among relapse related factors in schizophrenic patients.

- No statistically significant relation was found between relapse factors and socio economic level

- Negative correlation was noticed between social stigma and gender, between religion factor and medical disease, between community rehabilitation and medical disease, In addition to there was a negative correlation between total relapse and gender.

\section{Recommendations}

Based on findings of the present study, the following recommendations are suggested:

1. Primary mental health care must be enhanced to prevent relapse among mentally ill patients

2. 2- Other factors should be considered in further research such as the stress factors.

3. 3-Further studies are needed to investigate relapse related factors on larger sample size by another tools and in different setting.

4. Applying the mental health education and provision of effective and accessible community mental health services can help in reducing the relapse among schizophrenic patients.

5. Monitoring for prodromal symptoms of relapse by treatment providers, patients, family members, and others in frequent contact with the patient 


\section{References}

1. Abdel Salam, Z., Gaber, N., (2017): "Correlates to Relapse as Perceived by Schizophrenic Patients. American Journal of Nursing Science. Vol. 6, No. 4, 2017, pp. 308314. doi: 10.11648/j.ajns.20170604.15. Br J Psychiatry, vol. 195, no. 3, pp. 242-248.

2. Alvarez-Jimenez, Mario, (2012): "Risk factors for relapse following treatment for first episode psychosis: a systematic review and meta-analysis of longitudinal studies." Schizophrenia research139.1-3 116128.

3. Berton-Scarlet, B., (2019): Is a Positive Attitude Towards Ageing Associated with Diet in Middle-aged Cantabrians? (Doctoral dissertation, University of Otago).

4. Bloom, P., Das, A., \& Tavrow, A., (2018): Drugs Used in Substance Dependence. In Clinical Psychopharmacology (pp. 153166). Springer, Singapore.

5. Caspi,Amir, James M., McTiernan, \& Harry P., Warren, (2014): "Constraining solar flare differential emission measures with EVE and RHESSI." The Astrophysical Journal Letters 788.2: L31.

6. Chabungbam , G., Manchia, M., Pintus, R., Gerosa, C., Marcialis, M., \& Fanos, V., (2016): Fetal programming of neuropsychiatric disorders. Birth Defects Research Part C: Embryo Today: Reviews, 108(3), 207-223.

7. Chaurotia, V., Verma, K., \& Baniya, B., (2016): A Study of Psychosocial Factor Related with Relapse in Schizophrenia. IOSRJDMS, Volume 2016; 15(4): 26-34.

8. Fortinash, K., \& Worret, P., (2014): Psychiatric Mental Health Nursing-EBook. Elsevier Health Sciences. Current medical research and opinion, 34(9), 16131625.

9. Galletly, C., Castle, D., Dark, F., Humberstone, V.,Jablensky, A., Killackey, E., \& Tran, N., (2016): Royal Australian and New Zealand College of Psychiatrists clinical practice guidelines for the management of schizophrenia and related disorders. Australian \& New Zealand Journal of Psychiatry, 50(5), 410-472.

10. Haque, A., Kamal, A., De Laila, Z., Laila, L., Ahmed, H., \& Khan, N., (2015): Factors associated with relapse of schizophrenia. Bangladesh Journal of Psychiatry, 29(2), 59-63.

11. Henry, Paul Shala, 2016): "Method and apparatus for arranging communication sessions in a communication system." U.S. Patent No. 9,503,189. 22 Nov.

12. Insel, $\quad$ T., (2010): Rethinking schizophrenia. Nature, 468(7321), 187-193

13. Irish, A., Erickson, C., Wahls, T., Snetselaar, L., \& Darling, W., (2017): Randomized control trial evaluation of a modified Paleolithic dietary intervention in the treatment of relapsing-remitting multiple sclerosis: a pilot study. Degenerative neurological and neuromuscular disease, 7, 1.

14. Kastenbaum, R., (2015): Death, Society and Human Experience, Therapeutic advances in psychopharmacology, vol. 14, no. 3, pp. 203212.

15. Lorenz, T., (2016): The Two Towers: Social relevance and solid methods in applied positive psychology in the workplace (Doctoral dissertation

16. Miklowitz, David J., (2013): "Early intervention for symptomatic youth at risk for bipolar disorder: a randomized trial of familyfocused therapy." Journal of the American Academy of Child \& Adolescent Psychiatry 52.2 121-131.

17. Norcross, J., \& VandenBos, G., (2018): Leaving it at the office: A guide to psychotherapist self-care. Guilford Publications, 96.

18. Paul, Halmos, (2017): Lectures on ergodic theory. Courier Dover Publications, 111. JAMA psychiatry, 70(8), 812-820.

19. Pfiffner, C., Steinert, T., Kilian, R., Becker, T., Frasch, K., Eschweiler, G., \& Jaeger, S., (2014): Rehospitalization risk of former voluntary and involuntary patients with schizophrenia. Social psychiatry and psychiatric epidemiology, 49(11), 1719-1727.

20. Rice, A., (2018): Learning for leadership: Interpersonal and intergroup relations. vol. 44, no. Pt 2, pp. 193-207

21. San, L., Bernardo, M., Gomez A., \& Pena, M., (2013): Factors associated with relapse in patients with schizophrenia," Int J Psychiatry Clin Pract, vol. 17, no. 1, pp. 2-9

22. San, L., Bernardo, M., Gómez, A., Martínez, P., González, B., \& Peña, M., (2013): Socio-demographic, clinical and treatment characteristics of relapsing schizophrenic patients. Nordic journal of psychiatry, 67(1), 22-29.

23. Seligman, M., \& Darling, R., (2017): Ordinary families, special children,A systems approach to childhood disability, Guilford Publications, 115. 
24.Semrau, M., Evans-Lacko, S., Alem, A., Ayuso-Mateos, J., Chisholm, D., Gureje, O., \& Lund, C., (2015): Strengthening mental health systems in low-and middle-income countries: the Emerald programme. BMC medicine, 13(1), 79.

25.Sohlberg, M., \& Mateer, C., (2017): Cognitive rehabilitation, An integrative neuropsychological approach, Guilford Publications, 112.

26. Sun, B., Fan, N., Nie, S., Zhang, M., Huang, X., He, H., \& Rosenheck, R., (2014): Attitudes towards people with mental illness among psychiatrists, psychiatric nurses, involved family members and the general population in a large city in Guangzhou, China. International journal of mental health systems, 8(1), 26.

27. Tandon, R., Gaebel, W., Barch, D., Bustillo, J., Gur, R., Heckers, S., \& Van Os, J., (2013): Definition and description of schizophrenia in the DSM-5. Schizophrenia research, 150(1), 3-10.

28. Turkington, C., Mulholland, T., Rushe, R., Anderson, R., McCaul, S., Barrett, R., Barr \& S., Cooper, (2009): "Impact of persistent substance misuse on 1-year outcome in firstepisode psychos

29. Vijay, K., (2016): A specially designed semistructured scale, IOSR Journal of Medical Sciences (IOSR-JDMS), India, 2279, 2016.

30. W.H.O, (2012): Established the Kraepelinian Dichotomy and Schizophrenia but Then Reneged. In Schizophrenia Is a Misdiagnosis (pp. 63-91).

31. Webber, M., Corker, E., Hamilton, S., Weeks, C., Pinfold, V., Rose, D., \& Henderson, C., (2014): Discrimination against people with severe mental illness and their access to social capital: findings from the Viewpoint survey. Epidemiology and psychiatric sciences, 23(2), 155-165.

32. Wedding, D., \& Niemiec, R., (2014): Movies and mental illness: Using films to understand psychopathology. Hogrefe Publishing.

33. Werner, S., Malaspina, D., \& Rabinowitz, J., (2007): Socioeconomic status at birth is associated with risk of schizophrenia: population-based multilevel study. Schizophrenia bulletin, 33(6), 1373-1378. iology, 49(11), 1719-1727.

34. Whiteford, H., Ferrari, A., Degenhardt, L., Feigin, V., \& Vos, T., (2015): The global burden of mental, neurological and substance use disorders, an analysis from the Global
Burden of Disease Study 2010, PloS one, 10 (2), e0116820 (pp. 77-91).

35. Winter, S., Diamond, M., Green, J., Karasic, D., Reed, T., Whittle, S., \& Wylie, K., (2016): Transgender people: health at the margins of society. The Lancet, 388(10042), 390-400.

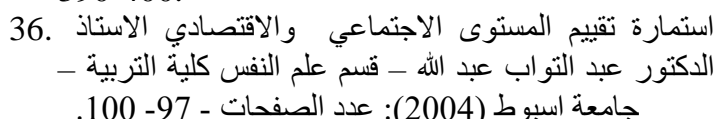

